\title{
Investigation of stope blast designs in a deep underground mine through vibration analysis
}

\author{
B Mohanty University of Toronto, Canada \\ D Zwaan University of Toronto, Canada \\ L Trivino University of Toronto, Canada
}

\begin{abstract}
A comprehensive blast monitoring program was carried out in multiple stopes at depths between 2,000 and 2,350 $\mathrm{m}$ levels in a deep underground copper-nickel mine. The diagnostic tools employed were multi-station high frequency $(>10 \mathrm{kHz})$ and high-g $(50-100 \mathrm{~g})$ triaxial accelerometers, at distances ranging from 10 to $50 \mathrm{~m}$ from the blasts. A total of over 30 production blasts were monitored in both low-stress and high-stress stopes, with the objective of determining the energy release characteristics of both single and multiple deck blasts, and identify the degree of malfunction if any in explosive energy release as indicated by the resulting blasting vibrations at these deep levels, and specific to each blast design. Packaged watergel explosives with an average charge weight of $35 \mathrm{~kg} /$ deck were employed in $162 \mathrm{~mm}$ diameter boreholes in these fan-drilled blasts. Analysis showed that only $30 \%$ of the explosive decks yielded acceptable levels of energy (40-100\% of the expected levels), whereas an equal number either failed or yielded $<40 \%$ of the expected vibration energy. It points to an unacceptable level of blast malfunctions, which would adversely affect dilution control and overall productivity. The various possible causes of these malfunctions have been discussed and remedial measures proposed to overcome these problems.
\end{abstract}

\section{Introduction}

With increasing demand for minerals, combined with depletion of surface and near surface deposits, it is natural that the industry is forced to explore as well as exploit deeper deposits. The problems associated with mining at increasing depths are well known. These may include any or all of the following: increased micro-seismicity, occurrence of rockbursts, stability and dilution control issues. In addition, higher in situ stress may cause excessive drill hole deviation, as well as deformation, i.e. progressive narrowing of drill holes, which may result in loss of drill holes entirely, and necessitate re-drilling of holes. In more acute cases, special de-stress blast designs have to be implemented to prevent drill hole deformation during or shortly after drilling and loading of holes with explosives. Among these variables and their downside effect on overall productivity, minimal attention has been paid to blast design and explosive usage, with the assumption that the same design criteria can be employed that have been routine for surface or mining at shallow depths.

The objective of this study is to examine the blast design practice in a systematic fashion in an underground operation in both stressed and unstressed stopes at Creighton Mine, Sudbury, Canada. The criterion for judging the efficiency of a blast design is based on the amplitude of the transmitted stress energy from detonation of individual deck charges, measured at various locations close to the blasts. Except for continuous cavity monitoring, there are no convenient means of assessing the results of large scale stope blasts in terms of blasting efficiency.

\section{$2 \quad$ Mining and blasting practice}

The majority of the stopes investigated are located deeper than 2,000 $\mathrm{m}$ level. The host rock consists of gabbro, norite and granites, and the copper-nickel orebodies consist of massive and semi-massive sulphides. The primary mining method employed at the mine is a modified version of vertical crater retreat 
mining (VRM). It involves drilling a raise bore or blasting a slot raise using large diameter boreholes. The production holes are then drilled off as parallel rows or rings. The typical procedure for mining a stope using the VRM method consists of raise boring (typically $1.2 \mathrm{~m}$ in diameter), and then drilling production holes $(162 \mathrm{~mm})$ as rings, and then blasting from the bottom up the stope in stages until the crown thickness has been reached. Figure 1 shows a typical ring layout (after Mohanty et al. 2013).

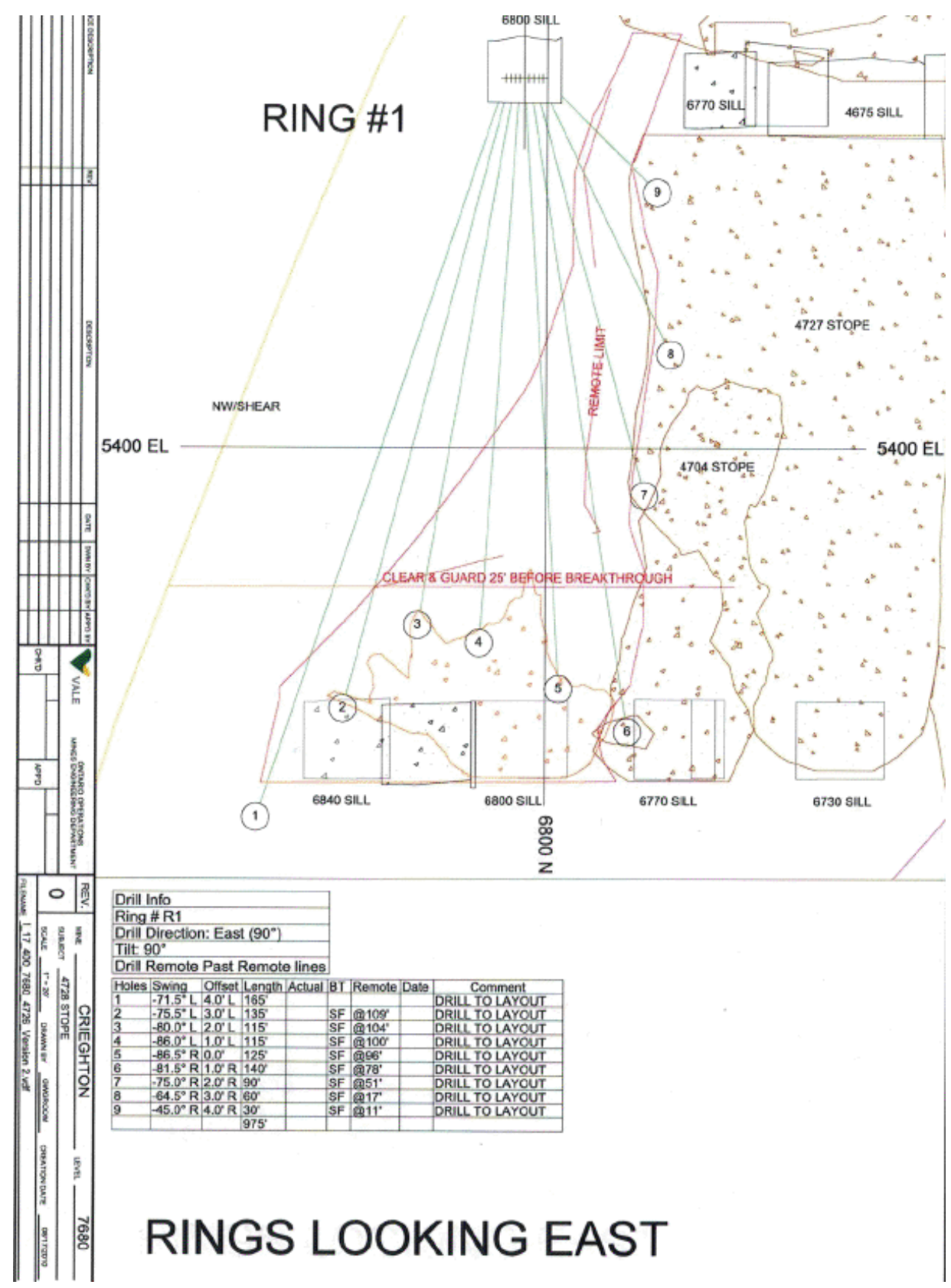

\section{Figure 1 Typical ring blast layout for VRM}

The VRM blasting operation consists of deck charges initiated with shock tube detonators. The blasts are set up with a detonating cord ( $4 \mathrm{~g} / \mathrm{m}$ of PETN) laid down on the top sill, which connects all the downline detonating cords in each borehole. A typical deck charge consists of a packaged water-gel explosive, initiated by a shock-tube detonator and a Pentolite booster. Each explosive deck has its own separate delay. The average charge weight in each deck is $35 \mathrm{~kg}$.

The boreholes are plugged at $1.2 \mathrm{~m}$ above the previous breakthrough. Crushed stone is used as the stemming material; the same is also used as inter-deck stemming, which typically measures 1-1.3 $\mathrm{m}$ in length. 


\section{$3 \quad$ Blast monitoring}

The vibration signals from the explosive decks were monitored by triaxial accelerometers. The individual accelerators were suitably bolted to the rock surface in a triaxial arrangement at multiple locations at varying distances ( $10-\sim 50 \mathrm{~m})$ from the blasts. These were high frequency $(>10 \mathrm{kHz})$ and high acceleration (typically 50 and $100 \mathrm{~g}$ ) sensors again suitably bolted to the rock surface, so that the vibrations recorded were true representation of the seismic energy transmitted from individual detonation of the explosive decks (Farnfield 1996; Segarra et al. 2009; Fleetwood et al. 2009). The acceleration signals were recorded by a suitable data acquisition system at a sampling rate of $50 \mathrm{kHz}$. A total of 31 production blasts at different stopes and in both unstressed and stressed stopes were recorded.

A typical layout of the stope and sensor locations is shown in Figure 2(a). The nature of the vibration signal received from a single deck of explosive charge is shown in Figure 2(b). The dominant frequency for the vibration signal is in excess of $600 \mathrm{~Hz}$. The resultant acceleration (i.e. vector sum of longitudinal, transverse, and vertical components) of vibrations from a typical ring blast is shown in Figure 3 for all three components: longitudinal, transverse and vertical. The designed delay times for the blast are also shown.

There is excellent agreement between the signals received at the two monitoring stations. The lower amplitude of the signals at station SMS 6 is to be expected, as it was much farther from the blast than station SMS 1. As expected, there is considerable scatter in firing times due to pyrotechnic nature of the delay detonators. However, low energy events as well as missing events corresponding to specific deck charges in particular are clearly evident in recordings at both stations.

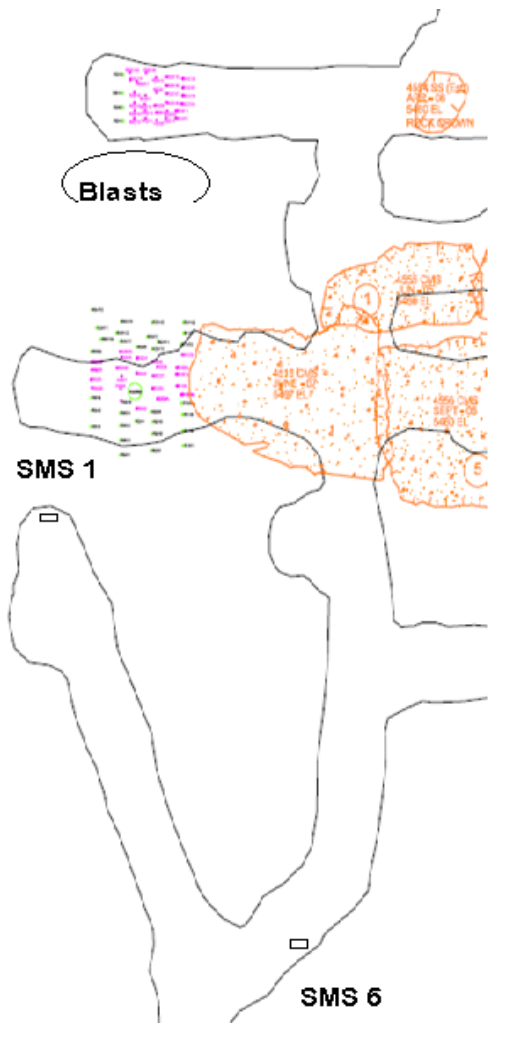

(a)

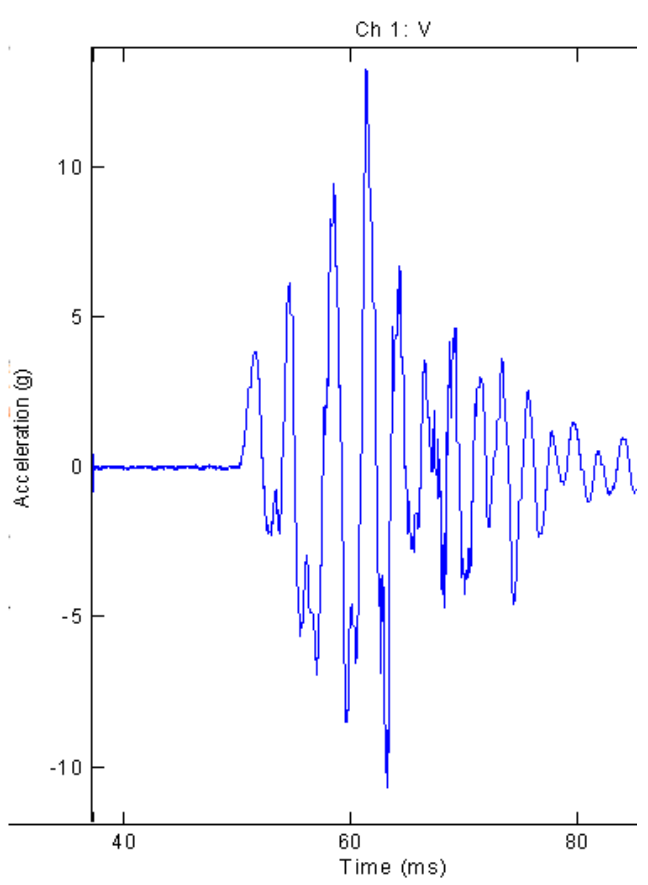

(b)

Figure 2 Typical blast layout and sensor locations in a stope blast, and the corresponding vibration signal (vertical component) received from a single deck of explosive 

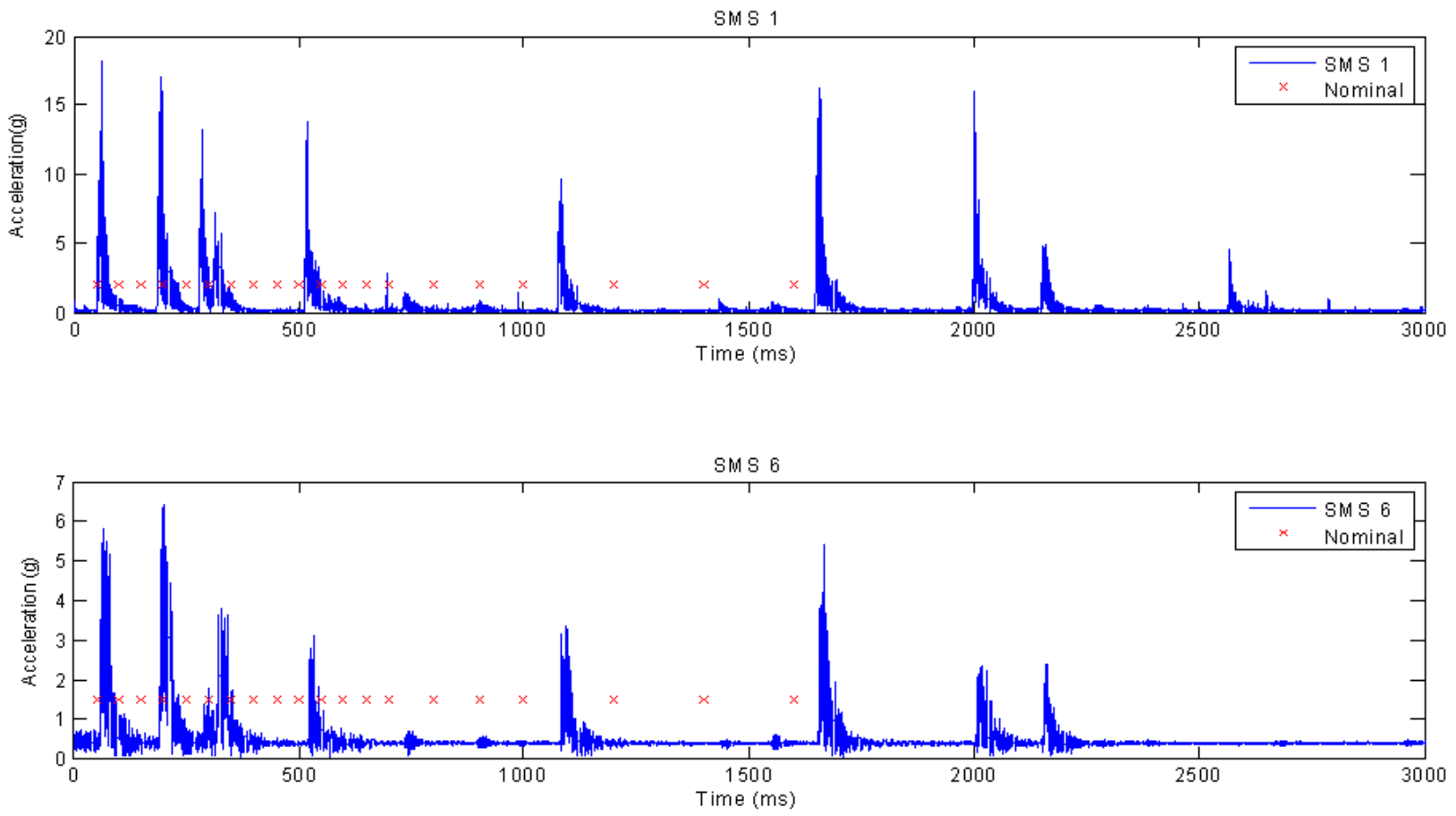

Figure 3 Resultant acceleration (longitudinal, transverse and vertical) at two locations from a stope blast; crosses indicate the designed delay times for each explosive deck for the initial part of the blast

\section{$4 \quad$ Analysis of vibration signals}

A typical vibration record obtained from a ring blast in Stope \#4726 involving a total of 21 explosive decks distributed among ten holes is shown in Figure 4. All three components of acceleration exhibit similar amplitudes, but there is considerable firing time scatter in the detonation of the explosive decks (nominal firing times shown as vertical lines). Besides the scatter, the missing decks are particularly noteworthy.

As before, the acceleration signals are converted to their vector sum either as resultant acceleration or particle velocity, after appropriate integration, for that location. It can be shown that square of either parameter is directly related to the transmitted stress energy from the explosive charge (Mohanty \& Yang 1997). The transmitted seismic energy, or shock energy, from detonation of an explosive deck relates directly to the detonation presssure and the shock energy content in the explosive, but it is only part of the total available energy in the explosive charge. However, all other blasting conditions remaining the same, the former does accurately represent the energy release characteristic of the explosive involved (Bjarnholt \& Holmberg 1976; Mohanty 1981; Mohanty 2000). The energy release from the various decks for the same blast is shown in Figure 5, with expected arrival times of detonation from the decks shown as vertical lines. 

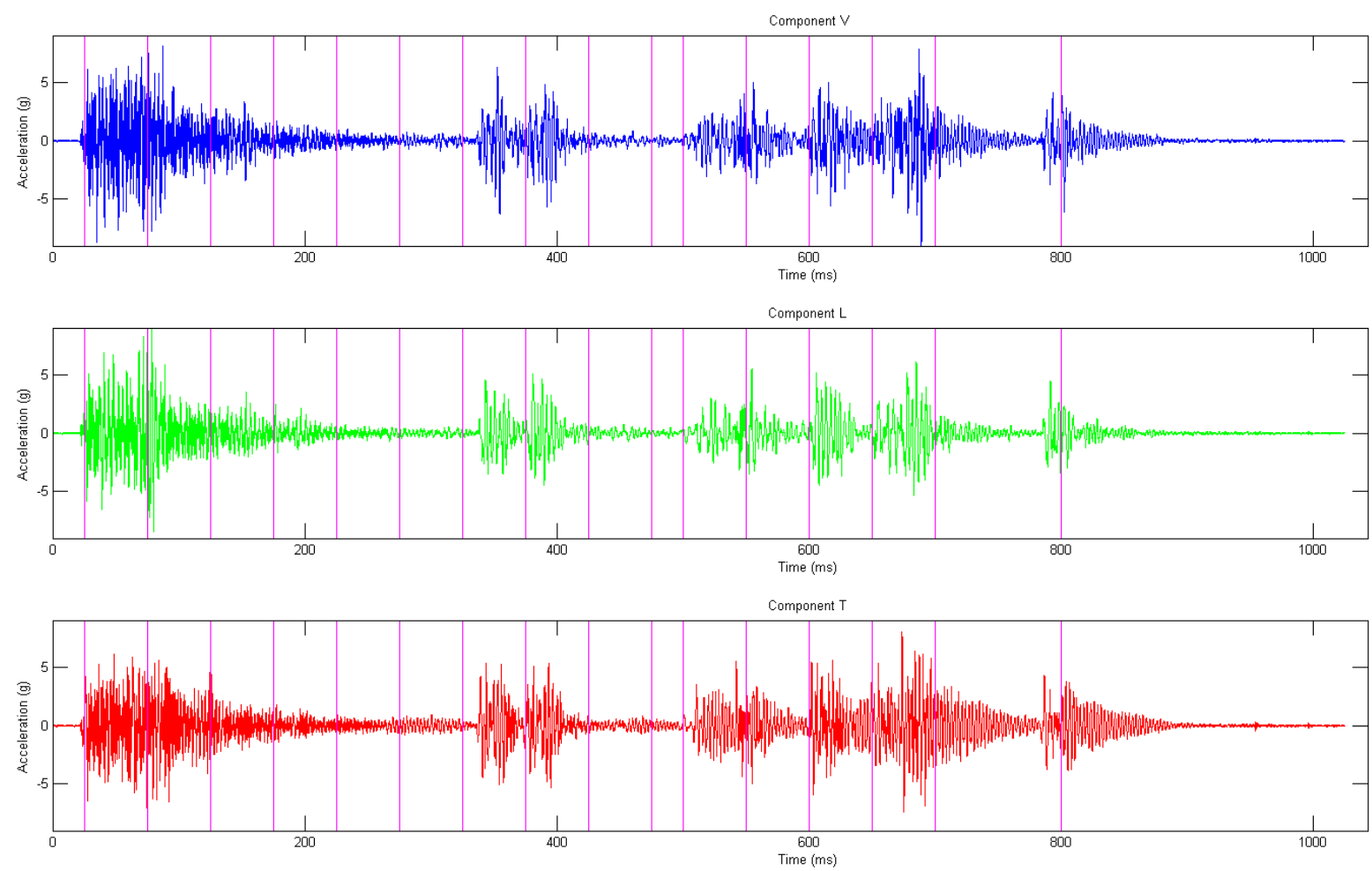

Figure 4 Near-field acceleration record (longitudinal, transverse and vertical) from a stope blast with decked explosive charges

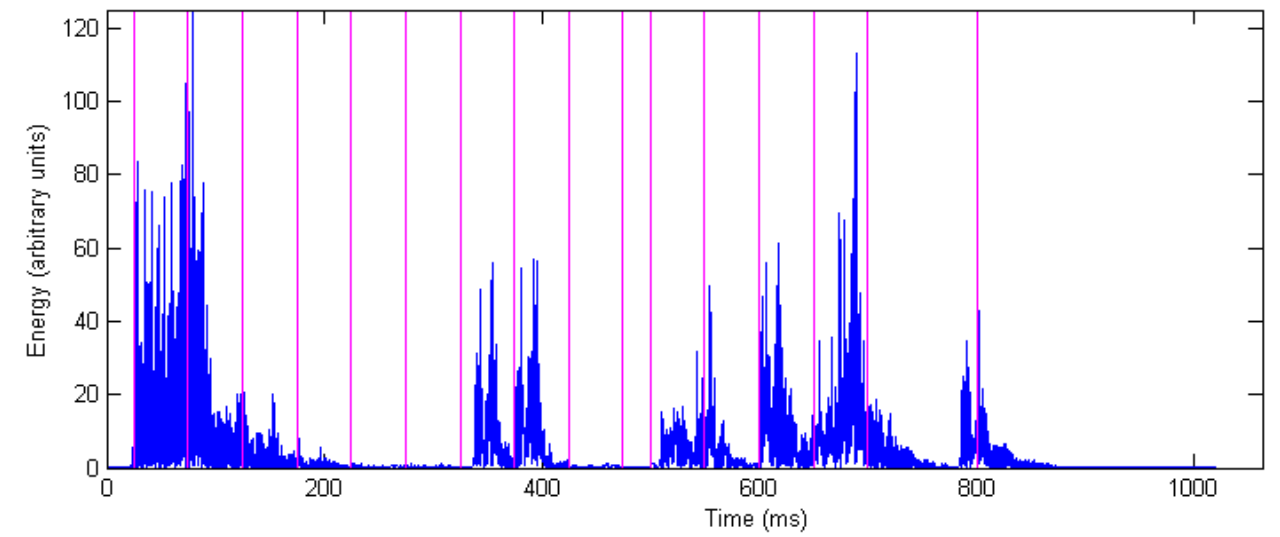

Figure 5 Transmitted vibration energy from the respective explosive decks in the stope blast; vertical lines indicating the design delay for each explosive deck

In assigning energy release figures from individual explosive decks with varying charge weights, these are normalised by simply dividing the amplitudes in Figure 5 by the corresponding charge weights for ease of comparison. The resulting normalised energy figures are shown in Figure 6, with the diameter of the circles representing the respective energy levels recorded for each explosive deck in the blast. Under all other conditions remaining more or less invariant for the near-field recording conditions as in this study, e.g. travel path, geology, explosive type, etc., all the circles should have had the same diameter. However, this is far from the case, as seen in Figure 6.

To further classify the degree of explosive malfunctions and account for any possible data scatter, the transmitted energy as indicated by the size of the circles in Figure 6 is denoted as weighted over a more flexible range. This is done by classifying the decks into 'full' energy, 'partial' energy, and 'failures'. Full energy decks denote any amplitude of events down to $40 \%$ or more of the maximum normalised energy release in Figure 5. Partial energy decks are represented by any normalised energy figures between 5 and 
$39 \%$ of the maximum; and the failed decks are resented by normalised energy of $<5 \%$ of the maximum. The radii of the normalised energy circles in Figure 6 reflect this classification. On this basis, there are seven failed decks, eight partial energy decks, and only six full energy explosive decks. This translates into only $\sim 30 \%$ of the explosive decks releasing acceptable vibration energy. However, the criterion of accepting energy release levels down to $40 \%$ of the maximum expected as being considered as full energy decks, as shown in Figures 6 and 7, would be considered very generous.

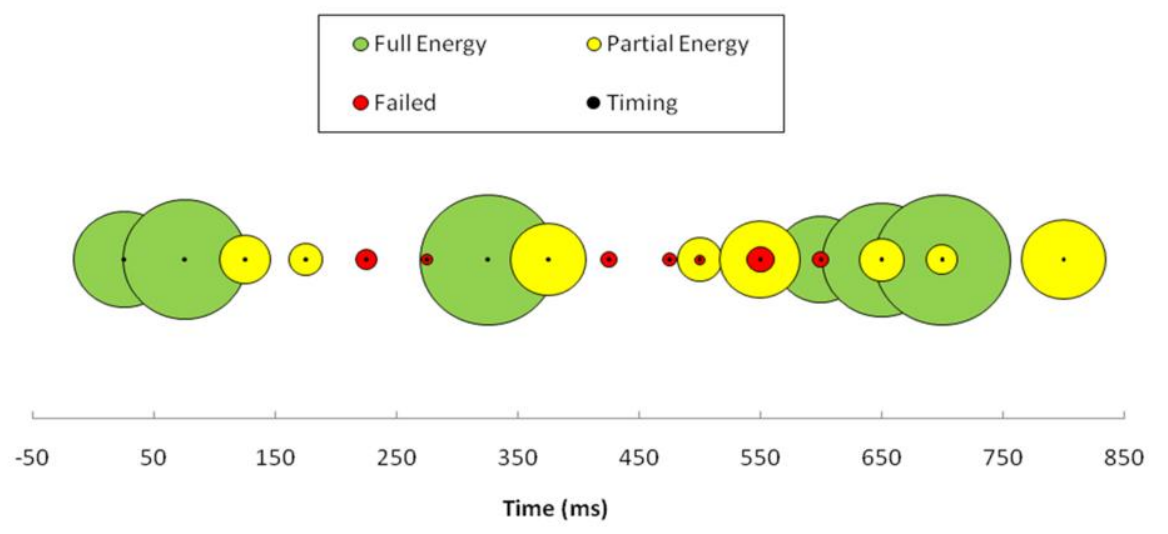

Figure 6 Examples of variable energy (normalised) release from the deck charges

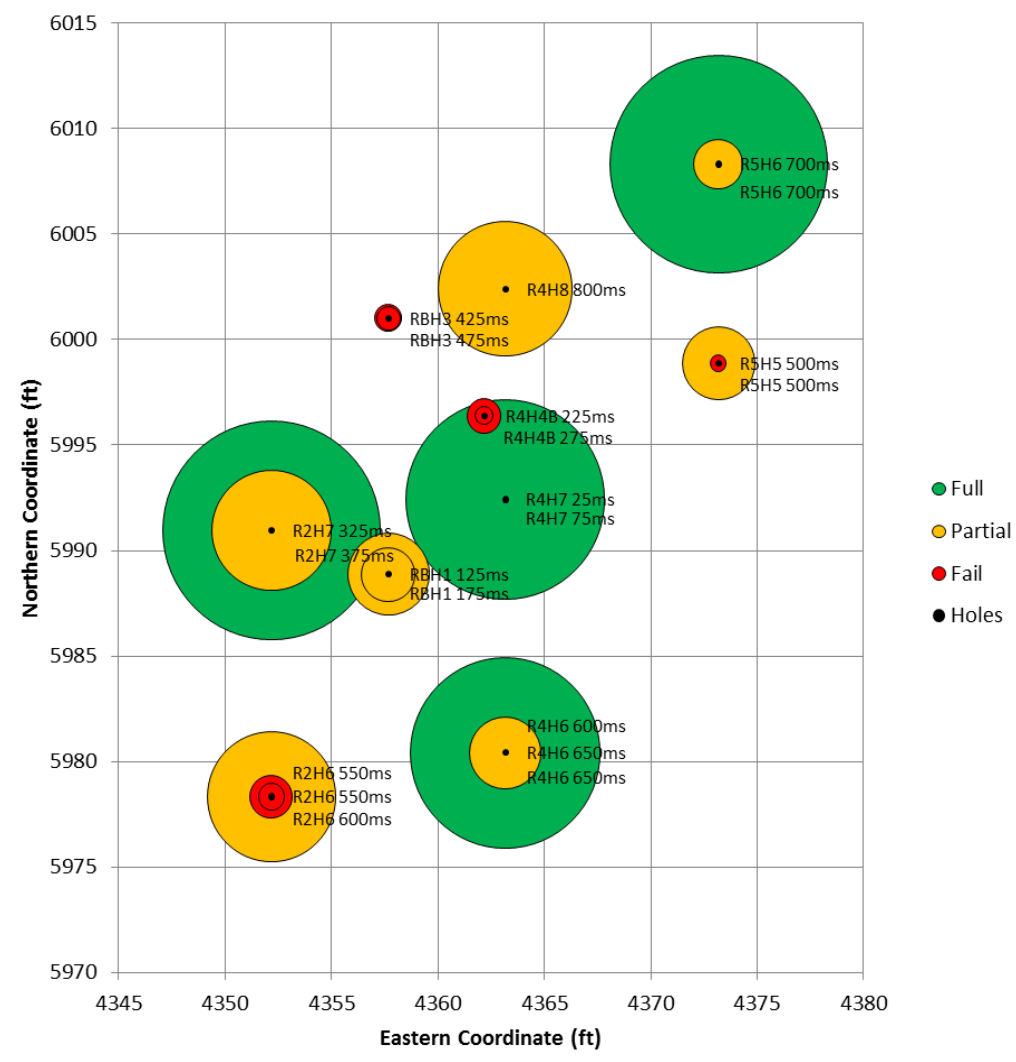

Figure 7 Plan view of a ring blast in a stope, with normalised energy circles representing magnitude of energy release by the explosive decks (nominal delay times shown for each deck (or single charge hole)

These findings are further illustrated in a plan view of the ring blast in question (Figure 7). It shows the approximate horizontal separation among the holes (but not taking into account the different depths of the respctive decks in each hole). The blast performance is presented again in normalised energy diameters as before. Multiple energy circles at the same location represent decked holes. The nominal delay times for 
the decks are also shown. It further illustrates the importance of deck location in a borehole (i.e. bottom or top) in assigning malfunctions, to be discussed subsequently.

The above results are typical in a general sense for all the 31 blasts studied in this investigation, irrespective of the state of stress in the stopes. To further illustrate the problem of blast malfunction, the results were analysed in terms of the number of holes employed in a given blast, with the assumption that it was possible that a larger number of holes in a blast leads to a higher percentage of malfunctions. The results of this analysis is shown in Figure 8 for multiple of five blast holes, ranging from 10 to 35 holes. The results show there is no significant diference in blast malfunctions, irrespective of the number of holes in a blast. All the blasts exhibited an unacceptable level of failed decks ( $30 \%)$ and at least the same number for partial-energy decks.

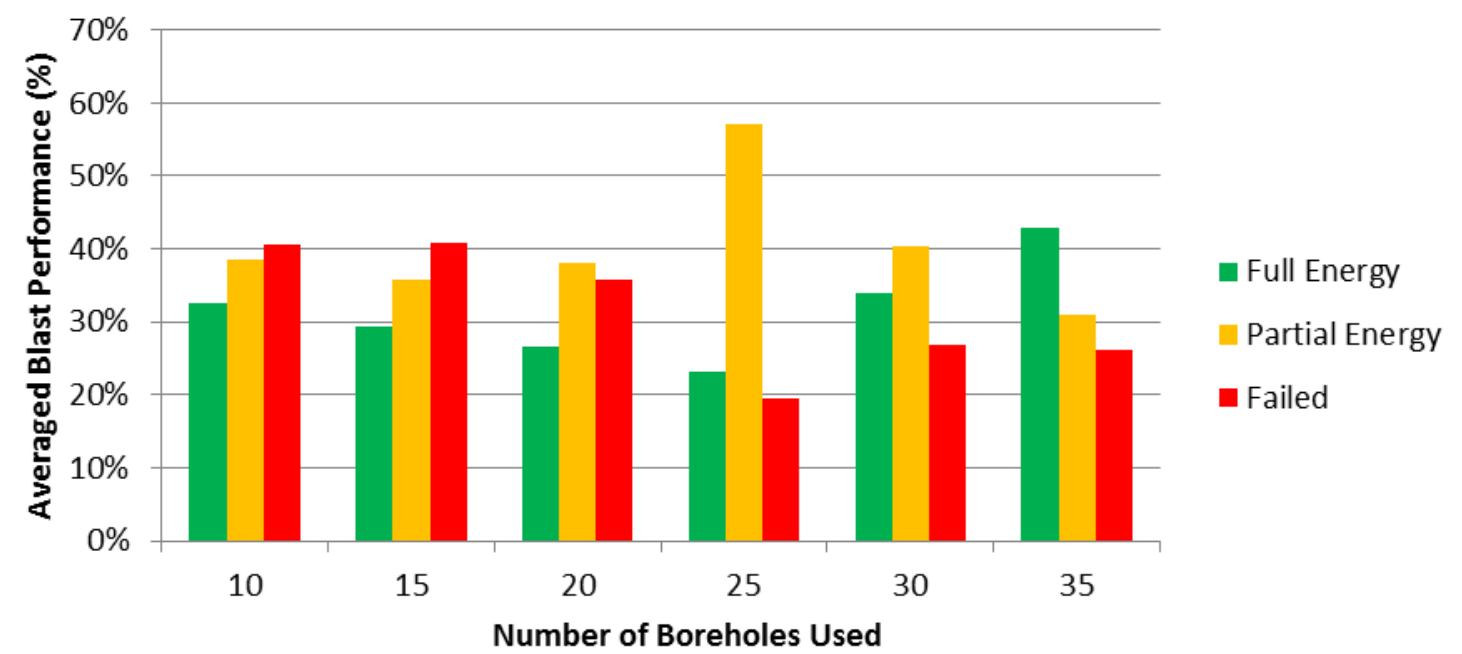

Figure 8 Average blast performance for blasts containing multiples of five boreholes

\section{Discussion}

The high rate of failure or partial failure, comprising over $60 \%$ of the explosive decks, requires an analysis of all the factors that might cause such malfunctions. First of all, the explosive products used in these blasts are standard commercial products with established reliability over decades. Therefore, it is the blast design that needs to be examined in detail to identify the cause of these malfunctions. Measurement of low or negligible vibration energy could be traced to any or combination of any of the following blasting conditions: a) loss of confinement, whereby the explosive deck detonates properly but against minimal burden, b) desensitisation due to the borehole squeezed below the critical diameter of the explosive due to high stresses, c) sympathetic pressure effects between holes and between decks in the same hole, and d) deleterious effect on explosive energy release due to tracing of the explosive decks by detonating cord ahead of initiation by booster. The role of these factors in blast malfunctions, especially in gassed explosive products has been studied in detail and appropriate remedial measures have been reported in literature (Lee et al. 2000; Mohanty 2009), but the adoption of some of these measures at the mine can only be viewed as part of a systematic and long-term investigation.

Some corrective measures against high stress levels have been adopted at the mine by introducing a de-stress blast design. This involved the drilling of $165 \mathrm{~mm}$ diameter, $18 \mathrm{~m}$ long hanging wall de-stress holes spaced $0.9 \mathrm{~m}$ apart progressed from the previously drilled panel to block boundary, but with mixed success. The principal objective of this measure was to facilitate drilling and subsequent loading of explosives rather than observing post-loaded behaviour of these holes or monitoring any improvement in blasting efficiency. Borehole camera survey has also showed significant deformation of the production blast holes soon after drilling has been completed. 


\section{$6 \quad$ Conclusions}

A systematic study of blasts in both unstressed and stressed stopes at significant depth has shown, on the basis of recorded vibration energy in the near-field, that only about one-third of the explosive decks in the conventional ring blasts yield the expected energy (i.e. 40 to $100 \%$ level). The rest of the decks appear either to fail $(<5 \%$ of the expected level) or yield very low energy $(<40 \%)$ in equal measure. This points to serious blast malfunctions, related to the current blast design and hole layout, but not necessarily the explosive product in use. The main cause of these malfunctions can be due to any combination of: borehole deviation resulting in loss of confinement, inadequate explosive deck spacing, inter-and intra-hole sympathetic pressure desensitisation of the gassed explosive products, explosive initiation practice, and borehole deformation especially in the highly stressed regions of the mine.

A long term program to investigate these issues, especially in holes with multiple decks and explosive initiation practice would be necessary to identify the main cause of these malfunctions. Monitoring of borehole deformation and deviation, in combination with de-stress blast techniques, e.g. efficiency of drilling large diameter perimeter holes, should be part of this effort. Without such measures, it will be difficult to control dilution and improve productivity at the mine which is particularly pertinent when operating at significant depths below surface.

\section{Acknowledgement}

The authors would like to thank Vale Canada Ltd. for the financial support and for facilitating this study at their Creighton Mine operation. Financial support by Natural Sciences and Engineering Research Council of Canada for the study is also gratefully acknowledged.

\section{References}

Bjarnholt, G \& Holmberg, R 1976, 'Explosives expansion work in underwater detonations', in DJ Edwards \& SJ Jacobs (eds), Proceedings of the 6th International Symposium on Detonation, US Government Printing Office, Washington, pp. 540-550.

Farnfield, R 1996, 'So you think you are monitoring peak particle velocity', Proceedings of the 12th Symposium on Explosives and Blasting Research, International Society of Explosives Engineers, Cleveland, pp. 13-20.

Fleetwood, KG, Villaescusa, E, Li, J \& Varden, R 2009, 'Comparison of traditional near-field vibration prediction models with three-dimensional vibration scaling and blast wave energy', in JA Sanchidrian (ed.), Proceedings of the 9th International Symposium on Rock Fragmentation by Blasting: FRAGBLAST 9, CRC Press, Boca Raton, pp. 579-588.

Lee, R, Rodgers, J \& Whitaker, K 2000, 'Explosives malfunctions in decked blasts', Proceedings of the 26th Annual Conference on Explosives and Blasting Technology, International Society of Explosives Engineers, Cleveland, pp. 25-34.

Mohanty, B 1981, 'Energy, strength and performance; and their implication in rating commercial explosives', Proceedings of the 7th Annual Conference on Explosives and Blasting Technology, International Society of Explosives Engineers, Cleveland, pp. 293-306.

Mohanty, B \& Yang, R 1997, 'Blasting vibrations and explosives performance', Proceedings of the 13th Annual Symposium on Explosives and Blasting Research, International Society of Explosives Engineers, Cleveland, pp. 15-28.

Mohanty, B 2000, 'The Underwater Test as a tool for rating explosives', Proceedings of the 26th Annual Conference Explosives and Blasting Technology, vol. 2, International Society Explosives Engineers, Cleveland, pp. 9-24.

Mohanty, B 2009, 'Intra-hole and inter-hole effects in typical blast designs and their implications on explosives energy release and detonator delay time-A critical review', in JA Sanchidrian (ed.), Proceedings of the 9th International Symposium on Rock Fragmentation by Blasting: FRAGBLAST 9, CRC Press, Boca Raton, pp. 23-31.

Mohanty, B, Zwaan, D \& Malek, F 2013, 'Diagnostics of Production Blasts in a Deep Underground Mine', Engineering and Mining Journal, pp. 52-57.

Segarra, P, Sanchidrian, JA, Lopez, JM, Querol, E \& Guiterrez, J 2009, 'Assessment of the error of blast vibration measurements', in JA Sanchidrian (ed.), Proceedings of the 9th International Symposium on Rock Fragmentation by Blasting: FRAGBLAST 9, CRC Press, Boca Raton, pp. 551-560. 